\title{
Pengaruh pH dan Konsentrasi Elektrolit dalam Elektrokoagulasi Limbah Surfaktan
}

\author{
Hanumi Oktiyani Rusdi*, Surjani Wonorahardjo, Yudhi Utomo, Anugrah Ricky Wijaya \\ Jurusan Kimia Fakultas Matematika dan Ilmu Pengetahuan Alam Universitas Negeri Malang \\ Corresponding author: hanumi.rusdi.fmipa@um.ac.id
}

\section{Article history}

Received: $30^{\text {th }}$ July, 2020

Received in revised form: $14^{\text {th }}$

August, 2020

Accepted: 29 ${ }^{\text {th }}$ August, 2020

DOI:

10.17977/um0260v4i12020p021

\section{Kata-kata kunci:}

Surfaktan

Elektrokoagulasi

Limbah

\begin{abstract}
Abstrak
Surfaktan merupakan komponen utama yang terdapat dalam bahan pencuci. Surfaktan dalam bahan pencuci akan membentuk lapisan yang menyebar pada permukaan air, sehingga dapat menurunkan tegangan muka, dan selanjutnya akan membentuk emulsi berupa busa yang dapat mengusir kotoran. Sejumlah besar surfaktan dalam air limbah yang dibuang ke lingkungan dapat mengakibatkan kerusakan kehidupan akuatik, mencemari air dan membahayakan kesehatan manusia. Oleh karena itu perlu dilakukan pemisahan atau perubahan menjadi bahan lain yang tidak berbahaya sebelum dibuang ke lingkungan. Salah satu metode yang digunakan adalah elektrokoagulasi. Metode elektrokoagulasi merupakan metode pengolahan limbah cair yang ramah lingkungan dengan menggabungkan prinsip koagulasi, flotasi dan elektrokimia. Pada penelitian ini dilakukan optimasi metode elektrokoagulasi dengan variasi $\mathrm{pH}$ dan konsentrasi elektrolit pada pengolahan limbah simulasi surfaktan. Kadar surfaktan ditentukan melalui ekstraksi pasangan ion surfaktan dan metilen biru dengan pelarut organik yang selanjutnya diukur menggunakan spektrofotometer. Optimasi metode dilakukan dengan menentukan panjang serapan maksimum, pengaruh $\mathrm{pH}$, dan pengaruh penambahan elektrolit dengan konsentrasi yang berbeda. Hasil penelitian menunjukkan bahwa serapan maksimum pada panjang gelombang $652 \mathrm{~nm}$. Persentase penurunan kadar surfaktan paling tinggi terjadi pada $\mathrm{pH} 2$ dengan penambahan elektrolit $\mathrm{Na}_{2} \mathrm{SO}_{4} 7 \mathrm{mM}$ yaitu osebesar $85,65 \%$.
\end{abstract}

\begin{abstract}
Surfactants are the main components in detergents. Surfactants in detergents will form a layer that spreads on the surface of the water, which can reduce the surface tension of the water and will form an emulsion the foam formation that can repel dirt. Large amounts of surfactants in wastewater discharged into the environment can cause damage to aquatic life, water pollution and endanger human health. Therefor it is necessary to separate or change them into other harmless materials before being discharged into the environment. One of the methods used is electrocoagulation. The electrocoagulation method is an environmentally friendly method of treating liquid waste by combining the principles of coagulation, floatation and electrochemistry. In this study, the electrocoagulation method was carried out by varying $\mathrm{pH}$ and electrolyte concentrations in the simulated surfactant waste treatment. Surfactant levels were determined by extraction of ion pair surfactant-methylene blue with an organic solvent then measured using spectrophotometer. The optimization of the method is done by determining the maximum absorption length, optimum $\mathrm{pH}$, and the effect of adding electrolytes with different concentrations. The results showed that the maximum absorption at a wavelength of $652 \mathrm{~nm}$. The highest percentage reduction in surfactant levels occurred in $\mathrm{pH} 2$ with the addition of $7 \mathrm{mM} \mathrm{Na}_{2} \mathrm{SO}_{4}$ electrolyte of $85.65 \%$
\end{abstract}




\section{PENDAHULUAN}

Surfaktan merupakan senyawa organik yang banyak digunakan untuk keperluan rumah tangga dan industri, terutama sebagai deterjen dalam bahan pembersih (Riyanto, 2014). Selain itu surfaktan banyak digunakan sebagai agen flokulasi dan wetting (Mańko, 2017), perekat (Bondarchuk, 2017) dan pengemulsi (Cheng, 2020) dan dalam industri minyak dan gas (Pal, 2016; Massarweh, 2020). Hal ini dikarenakan surfaktan memiliki sifat yang unik dari struktur molekulnya yaitu mampu menurunkan tegangan antarmuka dan membentuk misel (Babajanzadeh, 2019) sehingga memungkinkan partikel-partikel yang menempel pada bahan-bahan yang dicuci terlepas dan mengapung terlarut dalam air. Struktur molekul surfaktan terdiri atas gugus hidrofilik dan hidrofobik. Gugus hidrofilik yang akan berinteraksi dengan air dan gugus hidrofobik merupakan rantai hidrokarbon panjang yang tidak mudah larut dalam air (Babanjanzadeh, 2019).

Berdasarkan kelarutannya dalam air surfaktan digolongkan kedalam surfaktan ionik dan nonionik. Surfaktan ionik dapat dibedakan menjadi surfaktan anionik, kationik dan amfoter (Yuan, 2014). Salah satu surfaktan yang paling banyak digunakan dalam deterjen adalah surfaktan anionik karena sangat ampuh menghilangkan kotoran, tanah liat, dan beberapa noda berminyak. Kinerja surfaktan dimulai saat surfaktan ini perlu mengalami ionisasi. Ketika surfaktan anionik ditambahkan ke air akan mulai terionisasi dan menjadi bermuatan negatif. Kotoran, tanah liat, dan beberapa noda berminyak yang merupakan partikel bermuatan positif mengikat surfaktan bermuatan negatif yang juga sangat efektif dalam menghilangkan partikel tanah. Surfaktan anionik umumnya memberikan tingkat busa yang lebih tinggi dibandingkan dengan kelas surfaktan lainnya (Babajanzadeh, 2019). Sodium dodecyl sulfate (SDS) adalah salah satu surfaktan anionik golongan linear alkyl sulfates (Gambar 1) yang paling banyak dikomersialkan (Harendra, 2012).

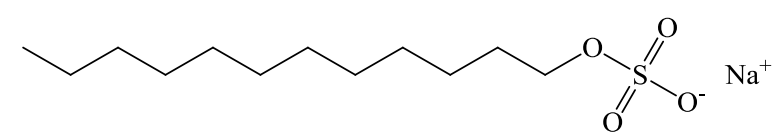

Gambar 1. Struktur molekul SDS (Arslan, 2017)
Limbah cair yang mengandung surfaktan dan dibuang ke lingkungan menyebabkan masalah pencemaran air. Ketika konsentrasi surfaktan mencapai $0.1 \mathrm{mg} / \mathrm{L}$, kemungkinan dalam air akan muncul busa secara terus menerus. Banyaknya gelembung yang terjadi tidak akan mudah hilang di dalam air, sehingga dapat membentuk lapisan isolasi busa. Lapisan isolasi ini menghambat proses pertukaran antara gas di atmosfer dan badan air yang menyebabkan pengurangan oksigen terlarut. Sejumlah besar mikro-organisme dapat mati karena hipoksia sehingga mengakibatkan kerusakan badan air (Yuan, 2014). Oleh karena itu perlu dilakukan pemisahan atau perubahan menjadi bahan lain yang tidak berbahaya sebelum dibuang ke lingkungan.

Berbagai proses pengolahan atau pemisahan surfaktan dalam limbah telah dilakukan, diantaranya dengan adsorpsi menggunakan berbagai adsorben seperti bahan komposit MCM41 (Ariapad, 2012), karbon aktif (Bindes, 2015), adsorben dolochar (Shami, 2019), menggunakan proses oksidasi $\mathrm{O}_{3} / \mathrm{UV} / \mathrm{H}_{2} \mathrm{O}_{2}$ (Arslan, 2017), menggunakan metode gabungan koagulasi/flokulasi/sedimentasi dengan membran (Nascimento, 2019) dan menggunakan reaktor membran aerobik termofilik (Collivignarelli, 2019). Pada penelitian ini digunakan metode elektrokoagulasi pada proses pengolahan limbah simulasi surfaktan yang dilanjutkan dengan pengukuran kadar surfaktan secara spektroforometer.

Elektrokoagulasi merupakan suatu metode alternatif dan ekonomis yang menggunakan prinsip elektrolisis (Gambar 2). Metode ini telah digunakan secara luas sebagai metode pengolahan air limbah dalam dekade terakhir (Jing, 2020). Metode ini banyak mendapat perhatian karena pengoperasiannya yang sederhana, efisiensi pembuangan (\% removal) yang tinggi, sedikit sludge yang dihasilkan, dan membutuhkan lebih sedikit bahan kimia (Abbas, 2018) sehingga teknologi elektrokimia ini dipandang lebih ramah lingkungan (Hashim, 2020).

Elektrokoagulasi merupakan metode yang menggabungkan prinsip koagulasi, flotasi dan elektrokimia (Hashim, 2020). Aluminum (Al) dan besi $(\mathrm{Fe})$ merupakan bahan yang umum digunakan sebagai elektroda. Saat arus listrik mengalir, anoda (M) terlarut membentuk ion $\mathrm{M}^{\mathrm{n}+}$ (disebut sebagai proses oksidasi) and $\mathrm{H}_{2} \mathrm{O}$ direduksi menjadi ion $\mathrm{OH}^{-}$dan gas $\mathrm{H}_{2}$ (disebut proses reduksi). Selanjutnya reaksi antara ion $\mathrm{M}^{\mathrm{n}+}$ 
dan ion $\mathrm{OH}^{-}$menghasilkan koagulan. Koagulan tersebut akan menyerap surfaktan untuk menghasilkan sludge. Selain itu, gas $\mathrm{H}_{2}$ mengalirkan polutan ke permukaan air limbah sebagai buih (flok) (Syaichurrozi, 2021).

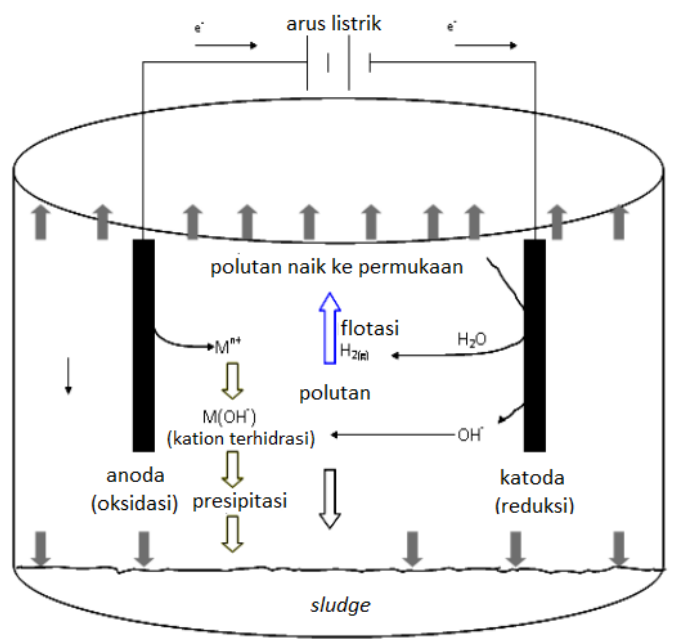

Gambar 2. Skema proses elektrokoagulasi

Reaksi elektrokimia yang terjadi adalah sebagai berikut (Mohebrad, 2017)

Pada anoda:

$$
\begin{aligned}
& \mathrm{M}(s) \rightarrow \mathrm{M}(a q)^{\mathrm{n}+}+\mathrm{n} e^{-} \\
& 2 \mathrm{H}_{2} \mathrm{O}(l) \rightarrow 4 \mathrm{H}^{+}(a q)+\mathrm{O}_{2}(g)+4 e^{-}
\end{aligned}
$$

Pada katoda:

$$
\begin{aligned}
& \mathrm{M}^{\mathrm{n}+}(a q)+\mathrm{n}^{-} \rightarrow \mathrm{M}(s) \\
& 2 \mathrm{H}_{2} \mathrm{O}(l)+2 e^{-} \rightarrow \mathrm{H}_{2}(a q)+2 \mathrm{OH}^{-}(a q)
\end{aligned}
$$

Beberapa parameter yang yang berpengaruh pada proses elektrokoagulasi yaitu jenis elektroda, susunan elektroda, arus, $\mathrm{pH}$, konduktivitas larutan, suhu, konsentrasi awal polutan, konsentrasi anion, kecepatan pengendapan dan jarak antarelektroda (Naje et al, 2016).

Pada penelitian ini dilakukan optimasi metode pada proses pengolahan limbah simulasi surfaktan secara elektrokoagulasi menggunakan elektroda besi. Elektroda besi mudah diperoleh, tidak beracun dan harganya lebih murah dibandingkan aluminium (Hakizima, 2017)). Optimasi metode dilakukan dengan mengetahui pengaruh $\mathrm{pH}$ dan penambahan elektrolit pendukung dalam menurunkan kadar surfaktan SDS. Kadar surfaktan SDS ditentukan dengan spektrofotometri sinar tampak menggunakan pereaksi metilen biru berdasarkan metode standar SNI 06-6989.51-2005.

\section{METODE}

Alat yang digunakan dalam penelitian ini adalah power supply DC, gelas kimia, pengaduk magnetik, gelas ukur, labu ukur, corong kaca, corong pisah, pipet volume, pipet ukur, pipet tetes.

Bahan-bahan yang digunakan dalam penelitian ini adalah surfaktan sodium dodecyl sulfat (SDS) p.a, pelat besi dengan kemurnian 99\% (dimensi: panjang $10 \mathrm{~cm}$, lebar $5 \mathrm{~cm}$, dan tebal $0,3 \mathrm{~cm})$, aquadest, kloroform $\left(\mathrm{CHCl}_{3}\right)$, metilen biru, $\mathrm{H}_{2} \mathrm{SO}_{4}, \mathrm{HNO}_{3}$, Natrium dihidrogen fosfat monohidrat $\left(\mathrm{Na}_{2} \mathrm{H}_{2} \mathrm{PO}_{4} \cdot \mathrm{H}_{2} \mathrm{O}\right)$.

Tahap pertama pada penelitian ini adalah penentuan panjang gelombang maksimum dari larutan standar SDS yang dilanjutkan dengan menentukan persamaan linear dari kurva kalibrasi yang diperoleh. Tahap selanjutnya merancang reaktor elektrokoagulasi yang akan digunakan. Reaktor elektrokoagulasi dirancang dengan sistem Batch menggunakan elektroda besi. Reaktor ini berkapasistas $500 \mathrm{~mL}$ yang terdiri dari power supply DC, pengaduk magnetik, kabel penjepit buaya, wadah sampel (gelas kimia 500 $\mathrm{mL}$ ), dan elektroda besi seperti ditunjukkan pada Gambar 3. Elektroda yang digunakan sebanyak dua buah sebagai anoda dan katoda yang berukuran panjang $10 \mathrm{~cm}$, lebar $5 \mathrm{~cm}$ dan tebal 0,3 $\mathrm{cm}$. Jarak antarelektroda adalah $5 \mathrm{~cm}$. Semua elektroda dihubungkan dengan arus listrik DC, yaitu satu elektroda dihubungkan dengan kutub positif sebagai anoda dan satu elektroda dihubungkan dengan kutub negatif sebagai katoda.

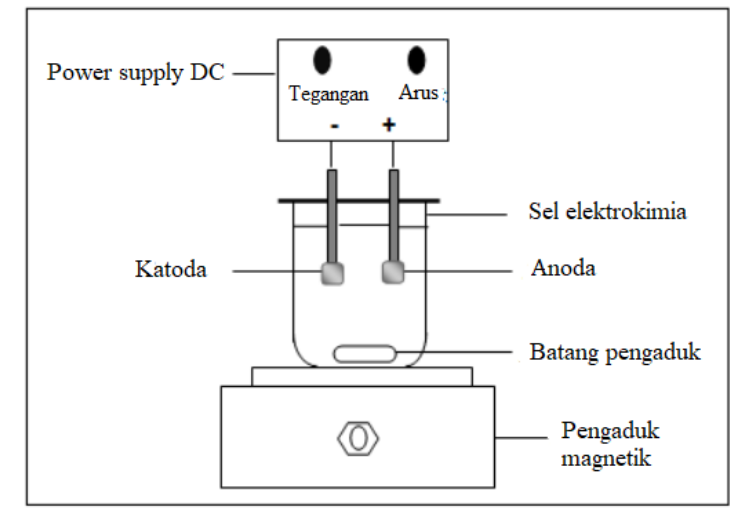

Gambar 3. Reaktor elektrokoagulasi dengan sistem Batch

Pada penelitian ini proses elektrokoagulasi dioptimasi dengan menggunakan parameter $\mathrm{pH}$ dan variasi konsentrasi elektrolit pada konsentrasi SDS yang tetap sebesar $50 \mathrm{ppm}$. Variasi $\mathrm{pH}$ yang digunakan yaitu 2, 5 dan 8 . Elektrolit yang 
ditambahkan adalah garam $\mathrm{Na}_{2} \mathrm{SO}_{4}$ dengan variasi konsentrasi $1 \mathrm{mM}, 3 \mathrm{mM}, 5 \mathrm{mM}$ dan $7 \mathrm{mM}$. Selanjutnya proses elektrokoagulasi dilakukan selama 60 menit dengan arus $3 \mathrm{~mA}$ dan tegangan 15 Volt. Setiap sampel hasil elektrokoagulasi disaring dan dilakukan pengukuran kadar surfaktan pada filtrat dengan spektrofotometer berdasarkan metode standar SNI 06-6989.512005. Pada metode ini digunakan pereaksi metilen biru yang dilanjutkan dengan ekstraksi menggunakan kloroform. Prinsip metode ini terjadi perpindahan metilen biru yang merupakan larutan kationik dari larutan air ke dalam larutan organik yang tidak dapat campur dengan air sampai pada titik jenuh (kesetimbangan). Perpindahan ini terjadi melalui pembentukan ikatan pasangan ion antara anion yang aktif dengan metilen biru, Methylene Blue Active Substance (MBAS) dan kation dari metilen biru. Intensitas warna biru yang dihasilkan dalam fasa organik merupakan ukuran dari MBAS yang sebanding dengan jumlah surfaktan (Sumarwanto, 2018).

Penentuan persentase penurunan kadar surfaktan $(\%$ removal $)$ dari proses elektrokoagulasi ditentukan dengan membandingkan perubahan konsentrasi surfaktan hasil elektrokoagulasi dengan konsentrasi awal (Mohebrad, 2017).

$$
\% \text { removal }=\frac{[\mathrm{SDS}]_{0}-[\mathrm{SDS}]_{\mathrm{t}}}{[\mathrm{SDS}]_{0}} \times 100
$$

\section{HASIL DAN PEMBAHASAN}

\section{Panjang Gelombang Maksimun dan Kurva Kalibrasi}

Panjang gelombang maksimum dari larutan standar SDS sebesar $652 \mathrm{~nm}$ yang diukur menggunakan Spektrometer UV-Vis. Penentuan panjang gelombang maksimum bertujuan agar dapat mengetahui serapan maksimum dari sampel yang mengandung SDS sehingga hasil pengukuran lebih akurat.

Pembuatan kurva kalibrasi dilakukan pada larutan standar SDS dengan konsentrasi 0,0 ppm, 0,4 ppm, 0,8 ppm, 1,2 ppm dan 2,0 ppm dengan nilai absorbansi disajikan pada Tabel 1 . Pembuatan kurva kalibrasi digunakan untuk menentukan persamaan regresi linear dimana persamaan yang diperoleh tersebut dapat digunakan dalam pencarian suatu kadar yang absorbansinya sudah diukur. Kurva kalibrasi merupakan grafik yang membentuk garis lurus yang menyatakan hubungan antara larutan kerja dan blanko dengan respon yang proporsional dari instrumen. Pada penelitian ini kurva kalibrasi dibuat dengan mengalurkan konsentrasi sederetan larutan standar SDS terhadap absorbansi. Grafik kurva standar SDS dapat dilihat pada Gambar 4 dengan nilai intercept 0,3178 , slope $=0,0039$ dan nilai korelasi $\left(\mathrm{R}^{2}\right)=0,9931$.

Tabel 1. Nilai absorbansi larutan standar SDS

\begin{tabular}{cc}
\hline $\begin{array}{c}\text { Konsentrasi larutan } \\
\text { standar SDS (ppm) }\end{array}$ & Absorbansi \\
\hline 0,0 & 0,00000 \\
\hline 0,4 & 0,15027 \\
\hline 0,8 & 0,26062 \\
\hline 1,2 & 0,35278 \\
\hline 2,0 & 0,65417 \\
\hline
\end{tabular}

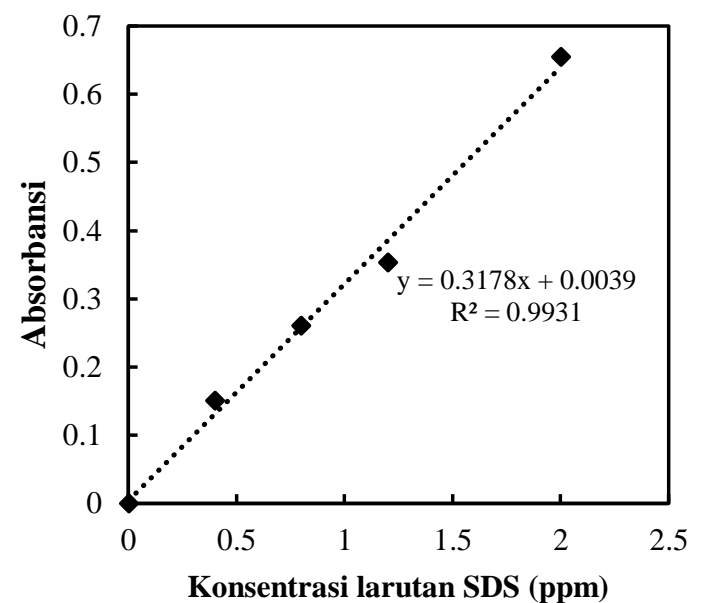

Gambar 4. Kurva kalibrasi larutan standar SDS

\section{Analisis pendahuluan}

Analisis pendahuluan dilakukan dengan mengukur perubahan konsentrasi SDS setelah proses elektrokoagulasi tanpa diberikan perlakuan perubahan $\mathrm{pH}$ maupun elektrolit. Konsentrasi SDS yang berperan sebagai limbah simulasi surfaktan pada penelitian ini sebesar $50 \mathrm{ppm}$. Tahapan ini bertujuan untuk mengetahui persentase penurunan kadar surfaktan yang terjadi tanpa adanya perlakuan perubahan parameter dan mengetahui keefektifan proses elektrokoagulasi dengan sistem reaktor yang dirancang.

Dari hasil pengukuran tersebut diperoleh konsentrasi SDS sebesar 18,10 ppm. Hal ini menunjukkan terjadinya penurunan kadar SDS sebesar 63,80\%. Dari hasil ini dapat dikatakan bahwa proses elektrokoagulasi dapat bekerja dengan baik yang mampu menurunkan kadar SDS lebih dari $50 \%$. Namun peningkatan efisiensi penurunan kadar surfaktan (\% removal) ini dapat ditingkatkan dengan melakukan optimasi pada 
Rusdi, H. O., Pengaruh pH dan Konsentrasi....

beberapa variabel dalam proses elektrokoagulasi. Pada penelitian ini dilakukan optimasi $\mathrm{pH}$ awal dan variasi konsentrasi elektrolit.

\section{Pengaruh pH awal}

$\mathrm{pH}$ dari medium larutan memiliki peran penting dalam proses elektrokoagulasi. $\mathrm{pH}$ dari medium larutan berubah selama proses elektrokoagulasi bergantung pada jenis elektroda dan kondisi pH awal (Abbas, 2017). Berdasarkan kondisi $\mathrm{pH}$, eektroda besi dapat membentuk dua jenis ion yaitu $\mathrm{Fe}^{2+}$ dan $\mathrm{Fe}^{3+}$. Adapun mekanisme reaksi yang terjadi di anoda dan katoda adalah sebagai berikut (Nwabanne, 2017; Jing, 2020).

Mekanisme 1 (suasana asam):

Anoda: $4 \mathrm{Fe}(s) \rightarrow 4 \mathrm{Fe}^{2+}(a q)+8 e^{-}$

$4 \mathrm{Fe}^{2+}(a q)+10 \mathrm{H}_{2} \mathrm{O}(l)+\mathrm{O}_{2}(g) \rightarrow 4 \mathrm{Fe}(\mathrm{OH})_{3}(s)+8 \mathrm{H}^{+}(a q)(3)$

Katode: $8 \mathrm{H}^{+}(a q)+8 e^{-} \rightarrow 4 \mathrm{H}_{2}(g)$

Total: $4 \mathrm{Fe}(s)+10 \mathrm{H}_{2} \mathrm{O}(l)+\mathrm{O}_{2}(g) \rightarrow 4 \mathrm{Fe}(\mathrm{OH})_{3}(s)+4 \mathrm{H}_{2}(g)(5)$

Mekanisme 2 (suasana basa):

Anoda: $\mathrm{Fe}(s) \rightarrow \mathrm{Fe}^{2+}(a q)+2 e^{-}$

$\mathrm{Fe}^{2+}(a q)+2 \mathrm{OH}^{-}(a q) \rightarrow \mathrm{Fe}(\mathrm{OH})_{2}(s)$

Katoda: $2 \mathrm{H}_{2} \mathrm{O}(l)+2 e^{-} \rightarrow \mathrm{H}_{2}(g)+2 \mathrm{OH}^{-}(a q)$

Total: $\mathrm{Fe}(s)+2 \mathrm{H}_{2} \mathrm{O}(l) \rightarrow \mathrm{Fe}(\mathrm{OH})_{2}(s)+\mathrm{H}_{2}(g)$

Dalam larutan, $\mathrm{Fe}(\mathrm{OH})_{\mathrm{n}}(s)$ terbentuk sebagai endapan amorf yang membantu menghilangkan polutan dari air limbah melalui pembentukan kompleks atau tarikan elektrostatik yang diikuti oleh koagulasi (Nwabanne, 2017; Mohebrad, 2017). Dalam hal ini endapan tersebut akan mengikat surfaktan SDS. Pada kondisi tertentu, beberapa senyawa kompleks dan polimer dapat terbentuk melalui reaksi hidrolisis dan polimerisasi akibat terlarutnya $\mathrm{Fe}$ secara elektrokimia (Jing, 2020).

Untuk mengetahui pengaruh dari $\mathrm{pH}$ awal terhadap \% removal kadar surfaktan, maka sampel limbah simulasi surfaktan (SDS) diatur pH-nya menggunakan larutan asam nitrat dan natrium hidroksida. Pengaturan $\mathrm{pH}$ awal pada sampel limbah simulasi dilakukan pada $\mathrm{pH} 2,5$ dan 8. Hal ini merujuk pada penelitian sebelumnya bahwa ionisasi besi memiliki rentang $\mathrm{pH}$ yang lebih luas dibandingkan aluminium (Naje, 2016) sehingga dilakukan pengaturan $\mathrm{pH}$ pada kondisi asam sampai basa. Hasil penelitian disajikan pada Tabel 2.
Tabel 2. Hasil \% removal kadar SDS pada variasi $\mathrm{pH}$

\begin{tabular}{cccc}
\hline \multirow{2}{*}{$\mathbf{p H}$} & \multicolumn{2}{c}{ Konsentrasi SDS (ppm) } & \multirow{\%}{\%}{$\begin{array}{c}\text { removal } \\
\text { kadar SDS }\end{array}$} \\
\cline { 2 - 3 } & awal & akhir & 75,06 \\
\hline 2 & 50,00 & 12,47 & 69.06 \\
\hline 5 & 50,00 & 15,47 & 65,67 \\
\hline 8 & 50,00 & 17,22 & \\
\hline
\end{tabular}

Pada kondisi asam $(\mathrm{pH}>1,5) \mathrm{Fe}^{3+}$ mudah terhidrolisis menjadi besi hidroksida sedangkan $\mathrm{Fe}^{2+}$ sangat stabil (Mbedzi, 2017). Selain itu, kation $\mathrm{Fe}^{2+}$ teroksidasi sangat lambat dengan adanya oksigen terlarut pada kondisi asam (Emamjomeh, 2011) sehingga koagulan yang berasal dari besi(III) lebih cepat terbentuk.

Koagulan akan semakin banyak terbentuk selama proses elektrokoagulasi berlangsung seiring dengan terjadi perubahan $\mathrm{pH}$ medium larutan. Pada kondisi awal asam, terjadi peningkatan $\mathrm{pH}$ secara berangsur-angsur mendekati kondisi netral atau basa dikarenakan adanya perubahan hidrogen (4) dan pembentukan ion hidroksida $\left(\mathrm{OH}^{-}\right)$(7) di katoda. Kondisi medium larutan yang mendekati daerah netral atau basa memiliki kelarutan yang rendah sehingga memungkinkan terbentuknya $\mathrm{Fe}(\mathrm{OH})_{3}$ atau $\mathrm{Fe}(\mathrm{OH})_{2}$ dan terjadi sweep coagulation yaitu penangkapan koloid negatif (SDS) dan ikut mengendap saat hidroksida logam tersebut terbentuk. Pada pH tinggi, akan terbentuk $\mathrm{Fe}(\mathrm{OH})_{4}^{-}$yang tidak efektif dalam pembentukan koagulan atau flok (Jing, 2020), sehingga pada daerah ini \% removal surfaktan SDS rendah.

Pada penelitian ini hasil efisiensi penurunan kadar surfaktan yang tinggi diperoleh ketika $\mathrm{pH}$ awal larutan berada dalam medium asam dan hal ini sejalan dengan penelitian yang pernah dilakukan oleh Bayar dan Nwabanne (Bayar, 2011; Nwabanne, 2017).

\section{Pengaruh konsentrasi elektrolit $\mathrm{Na}_{2} \mathrm{SO}_{4}$}

Elektrolit adalah larutan yang dapat menghantarkan listrik. Penambahan elektrolit pendukung ke dalam proses elektrokoagulasi memiliki dua pengaruh yaitu meningkatkan kekuatan ionik air dan meningkatkan konduktivitas listrik air yang menyebabkan lebih banyak arus yang melewati rangkaian sel pada potensial yang sama (Ghernaout, 2011). Selain itu penambahan elektrolit dapat memperkecil kelarutan sehingga mempercepat proses koagulasi.

Untuk mengetahui pengaruh penambahan elektrolit garam pada efektivitas elektrokoagulasi 
ditambahkan garam natrium sulfat $\left(\mathrm{Na}_{2} \mathrm{SO}_{4}\right)$ pada sampel limbah simulasi surfaktan SDS dengan berbagai variasi konsentrasi yang selanjutnya dielektrokoagulasi pada $\mathrm{pH}$ 2. Pemilihan $\mathrm{Na}_{2} \mathrm{SO}_{4}$ sebagai elektrolit dikarenakan ion sulfat mampu memecah emulsi yang lebih besar dibandingkan ion klorida jika berada pada medium bermuatan listrik dan membantu pembentukan endapan atas terbentuknya ion hidrokso polimer (Ghernaout, 2011) pada larutan. Selain itu di dalam larutan, $\mathrm{Na}_{2} \mathrm{SO}_{4}$ menghasilkan tiga ion yang berasal dari ion $\mathrm{Na}^{+}$dan $\mathrm{SO}_{4}{ }^{2-}$ sesuai dengan reaksi:

$\mathrm{Na}_{2} \mathrm{SO}_{4}(a q) \rightarrow 2 \mathrm{Na}^{+}(a q)+\mathrm{SO}_{4}{ }^{2-}(a q)$

Arus listrik dibawa melalui larutan ion $\mathrm{Na}^{+} \mathrm{ke}$ elektroda negatif dan ke elektroda positif oleh ion $\mathrm{SO}_{4}{ }^{2-}$. Semakin banyak jumlah ion dalam larutan dapat meningkatkan konduktivitas. Efisiensi penambahan elektrolit $\mathrm{Na}_{2} \mathrm{SO}_{4}$ pada proses elektrokoagulasi telah dilakukan pada pengolahan air limbah berminyak (Saeeddi, 2011) dan pengolahan air limbah yang mengandung Escherichia coli (Ndjomgoue-Yossa, 2014).

Hasil pengukuran pada penelitian ini disajikan pada Tabel 3. Hasil pengukuran menunjukkan bahwa konsentrasi $\mathrm{Na}_{2} \mathrm{SO}_{4} 7 \mathrm{mM}$ memberikan nilai \%removal yang paling besar yaitu $85,65 \%$. Meningkatnya konsentrasi elektrolit menyebabkan semakin banyak jumlah ion yang terlepas ke dalam larutan sehingga konduktivitas listrik air meningkat dan proses pembentukan koagulan atau flok semakin banyak dan cepat. Terbentuknya koagulan atau flok yang semakin banyak ini akan mengikat surfaktan SDS yang

\section{DAFTAR RUJUKAN}

Abbas, S.H., Ali, W. H. 2018. Electrocoagulation Technique Used To Treat Wastewater: A Review. American Journal of Engineering Research, 7(10), 74-88.

Ariapad, A., Zanjanchi, M.A., Arvand, M. 2012. Efficient removal of anionic surfactant using partial template-containing MCM41. Desalination, 284, 142-149.

Arslan, A., Topkaya, E., Bingol, D., Veli, S. 2017. Removal of anionic surfactant sodium dodecyl sulfate from aqueous solution by $\mathrm{O}_{3} / \mathrm{UV} / \mathrm{H}_{2} \mathrm{O}_{2}$ advanced oxidation process: Process optimization with response surface methodology approach. Sustainable Environment Research, xxx, 1- 7 .

Babajanzadeh, B., Sherizadeh, S., Ranji, H. 2019. Detergents and surfactants: a brief banyak sehingga dapat menurunkan kadar SDS dalam larutan dan memberikan persentase penurunan kadar SDS yang besar. Namun, penambahan elektrolit $\mathrm{Na}_{2} \mathrm{SO}_{4}$ sebesar $7 \mathrm{mM}$ ini belum dapat dikatakan optimum karena nilai \%removal yang diperoleh masih menunjukkan peningkatan sejalan dengan meningkatnya konsentrasi sehingga perlu dilakukan penambahan variasi konsentrasi $\mathrm{Na}_{2} \mathrm{SO}_{4}$ untuk mengetahui puncak \% removal dan penurunan \% removal. Berdasarkan teori penambahan konsentrasi elektrolit yang tinggi dapat menyebabkan terjadinya penurunan pembentukan koagulan karena adanya reaksi intermediate besi hidroksida dengan ion sulfat (Ghernaout, 2011; Mohebrad, 2017).

Tabel 3. Hasil \% removal kadar SDS pada variasi konsentrasi elektrolit

\begin{tabular}{cccc}
\hline $\begin{array}{c}\text { Konsentrasi } \\
\mathbf{N a}_{2} \mathbf{S O}_{4} \\
(\mathbf{m M})\end{array}$ & \multicolumn{2}{c}{$\begin{array}{c}\text { Konsentrasi SDS } \\
(\mathbf{p p m})\end{array}$} & $\begin{array}{c}\text { \% } \\
\text { kadar SDS }\end{array}$ \\
\cline { 2 - 3 } & awal & akhir & \\
\hline 1 & 50,00 & 12,50 & 75,00 \\
\hline 3 & 50,00 & 12,15 & 75,70 \\
\hline 5 & 50,00 & 10,89 & 78,22 \\
\hline 7 & 50,00 & 7,18 & 85,65 \\
\hline
\end{tabular}

\section{KESIMPULAN}

Dari hasil penelitian ini dapat disimpulkan bahwa metode elektrokoagulasi pada pengolahan limbah simulasi surfaktan SDS berlangsung pada $\mathrm{pH} 2$ dengan penambahan konsentrasi elektrolit $\mathrm{Na}_{2} \mathrm{SO}_{4} 7 \mathrm{mM}$ menghasilkan \%removal kadar SDS sebesar $85,65 \%$.

review. Open Access Journal of Science, 3(3), 94-99.

Bayar S., Yildiz, Y.S., Yilmaz, A.E., Irdemez, S. 2011. The effect of stirring speed and current density on removal efficiency of poultry slaughterhouse wastewater by electrocoagulation method. Desalination, 280, 103-107.

Bindes, M. M. M., Franco Jr., M. R. 2015. Surfactant removal from aqueous solutions onto activated carbon using UV spectroscopy, Desalination and Water Treatment, 56(11).

Bondarchuk, N. et al. 2017. Vacuum-anneling induces sub-surface redox-states in surfactant-structured $\quad \alpha-\mathrm{Fe}_{2} \mathrm{O}_{3}$ photoanodes prepared by ink-jet printing. Applied Catalysis B: Environmental, 211, 289-295 
Cheng, Y., Yuan, S. 2020. Emulsification of Surfactant on Oil Droplets by Molecular Dynamics Simulation. Molecules, 25(13), 3008

Collivignarelli, M.C., Miino, M.C., Baldi, M., Manzi, S., Abba, A. Bertanza, G. 2019. Removal of non-ionic and aninic surfactants from real laundry wastewater by means of a full-scale treatment system. Process Safety and Environmental Protection, 132, 105-115.

Danial, R., Abdullah, L. C., Mobarekeh, M. N., Sobri, S., Adnan, N. M. 2015. A Comparison between Aluminium and Iron Electrodes in Electrocoagulation Process for Glyphosate Removal. Jurnal Teknologi, 77(32), 21-26.

Emamjomeh, M. M., Sivakumar, M., Varyani, A. S. 2011. Analysis and the understanding of fluoride removal mechanisms by an electrocoagulation/flotation $\quad(\mathrm{ECF})$ process. Desalination, 275, 102-106.

Ghernaout, D. 2011. On the Controversial Effect of Sodium Sulphate as Supporting Electrolyte on Electrocoagulation Process: A Review. Desalination and Water Treatment, 27, 243-254.

Hakizima, J.N., Gourich, B., Chafi, M., Stiriba, Y., Vial, C., Drogui, P., Naja, J. 2017. Electrocoagulation process in water treatment: A review of electrocoagulation modeling approaches. Desalination, 404, $1-21$

Harendra, S., Vipulanandan, C. 2012. Determination of Sodium Dodecyl Sulfate (SDS) and Biosurfactants Sorption and Transport Parameters in Clayey Soil. Journal of Surfactants and Detergents, 15(6), 805-813.

Hashim, K.S.; AlKhaddar, R.; Shaw, A.; Kot, P.; Al-Jumeily, D.; Alwash, R.; Aljefery, M.H. Electrocoagulation as an ecofriendly river water treatment method. In Advances in Water Resources Engineering and Management, 219-235.

Jing, G., Ren, S, Gao, Y., Sun, W., Gao, Z. 2020. Electrocoagulation: A Promising Method to Treat and Reuse Mineral Processing Wastewater with High COD. Water, 12(595), 1-12.

Manko, D., Zdziennicka, A., Janczuk, B. 2017. Composition of Surface Layer at the Water-Air Interface and Micelles of Triton X-100 + Rhamnolipid Mixtures.
Journal of Solution Chemistry, 46, 12511271.

Massarweh, O., Abushaikha, A.S. 2020. The use of surfactants in enhanced oil recovery: A review of recent advances, 6, 3150-3178.

Mbedzi, N., Ibana, D., Dyer, L., Browner, R. 2017. The effect of oxidant addition on ferrous iron removal from multi-element acidic sulphate solutions. AIP Conference Proceedings, 1805, 030002.

Mohebrad, B., Dehghani, S., Rezaee, A. 2017. Anionic Surfactant Removal Using Electrochemical Process: Effect of Electrode Materials and Energy Consumption. Iranian Journal of Health, Safety \& Environment, 5(2), 939-946.

Moussa, D. T., El-Naas, M.H., Nasser, M., AlMarri, M.J. 2016. A comprehensive review of electrocoagulation for water treatment: Potentials and challenges, Journal of Environmental Management, $x x x, 1-18$.

Naje, A. S., Chelliapan, S., Zakaria, Z., Ajeel, M.A., Alaba, P.A. 2016. A review of electrocoagulation technology for the treatment of textile wastewater. Rev Chem Eng, 33(3), 263-292.

Nascimento, C. O.C., Veit, M. T., Palacio, S.M., Goncalves, G.C., Fagundes-Klen, M. R. 2019. Combined Application of Coagulation/Flocculation/Sedimentation and Membrane Separation for the Treatment of Laundry Wastewater. International Journal of Chemical Engineering, 2019, 1-13.

Ndjomgoue-Yossa, A. C., Nanseu-Njiki, C. P. 2014. Effect of electrode material and supporting electrolyte on the treatment of water containing Escherichia coli by electrocoagulation. International Journal of Environmental Science and Technology, 12, 2103-2110.

Nwabanne, J.T., Obi, C.C. 2017. Abbatoir Wastewater Treatment by Electrocoagulation Using Iron Electrodes. Der Chemica Sinica, 8(2), 254-260.

Pal, N., Babu, K., Mandal, A. 2016. Surface tension, dynamic light scattering and rheological studies of a new polymeric surfactant for application in enhanced oil recovery. Journal of Petroleum Science and Engineering, 146, 591-600.

Riyanto, Hidayatillah, A. 2014. Electrocoagulation of Detergent 
Wastewater Using Aluminium Wire Netting Electrode (AWNE). Proceeding of International Conference on Research, Implementation and Education of Mathematics and Sciences,Implementation and Education of Mathematics and Sciences, Yogyakarta: 18-20 May 2014, 151-158.

Saeedi, M., Khalvati-Fahlyani, A. 2011. Treatment of oily wastewater of a gas refinery by electrocoagulation using aluminum electrodes. Water Environ Res., 83(3), 256-64.

Shami, S., Dash, R. R., Verma A. K., Dash, A. K., Pradhan, A. 2019. Adsorptive removal of surfactant using dolochar: A kinetic and statistical modelling approach. Water Environment Research, 92(2), 222-235.
Sumarwanto, P., Hartati, Y. 2018. Penanganan Air Limbah Cucian Alat Gelas Laboratorium Dengan Metode Spektrometri Menggunakan Pereaksi Biru Metilen. Indonesia Laboratory of Journal, 1(1), 11-15.

Syaichurrozi, I., Sarto, S., Sediawan, W. B., Hidayat, M. 2021. Effect of Current and Initial $\mathrm{pH}$ on Electrocoagulation in Treating the Distillery Spent Wash with Very High Pollutant Content. Water, 13(1), 1-20.

Yuan, C.L., Xu, Z. Z., Fan, M. X., Liu, H. Y., Xie, Y. H., Zhu, T. 2014. Study on characteristic and harm surfactants. Journal of Chemical dan Pharmaceutical Research, 6(7), 2233-2237. 